\title{
Culture and Online Learning: Global Perspectives and Research
}

Editors: Jung, I., \& Gunawardena, C. N. (Eds.). (2014). Culture and online learning: Global perspectives and research. Sterling, VA: Stylus.

Reviewed by: Svenja Bedenlier, M.A., Carl von Ossietzky University Oldenburg, Germany

Despite the vast body of research on online learning and distance education, one of the areas in need of further analysis is its relation to culture and globalization (Zawacki-Richter, 2009). Thus, contributions by authors with international research backgrounds in this field hold the promise for Culture and Online Learning: Global Perspectives and Research to help minimize this perceived gap. Throughout the seventeen chapters of the book, the authors present a range of themes related to culture and online learning, mirroring their different perspectives and takes on this topic.

Gunawardena's statement in chapter eight on student support reiterates that, "We need to understand the online learner in context and in relation to the course, instructors, peer groups, workplace, family, culture, and society" (p. 89). Thus, considering the online learner as being embedded in diverse and overlapping forms of culture on the micro-, meso-, and macro-level, is a core recognition which the book is centered around.

Evidenced in the course of the book, Gunawardena's observation not only applies to support systems, but ranges from considerations of gender (Latchem, Chapter 12), leadership (Beaudoin, Chapter 11), faculty development (Gunawardena \& Jayatilleke, Chapter 7) to the mindful use of icons and images (Knight, Gunawardena, Barberà \& Aydin, Chapter 14) and students' differing expectations and perception of quality (Sangrà, Porto \& Jung, Chapter 9; Chen, Shen, Fukuda \& Jung, Chapter 16). Gunawardena's statement above shows both a simplicity and complexity of the relation between culture and online learning. Simplicity, because this sentence directs very plainly towards what ideally should be done. Complexity, because, as several chapters of this book show, theoretical conceptions and applications show the many layers of the field, which might be overlooked in superficial research and practice.

The first three chapters show that complexity is added through culture being a theoretical construct that needs to be translated into an applied context-without reducing culturally heterogeneous students to stereotypes. In their introductory chapter, Jung and Gunawardena point to different understandings of culture and how these have shifted from "a bipolar dimensional view to a more holistic view" (p. 5); to them the terms idioculture (Fine, 1979, p. 734 as cited on p. 7) and cyberculture (Breslow \& Mousoutzanis, 2012, p. xii as cited on p. 7) capture best the interrelatedness of culture and online learning. Jung then touches upon how culture permeates learning and the acceptance of technology and how this plays out in the online learning context (Chapters 2 and 3). 
The ensuing chapters address the importance of developing adequate instructional design (Frechette, Layne \& Gunawardena, Chapter 6), leaving students the space to build and negotiate an online identity (Gunawardena, Chapter 4), and herein potentially educating global digital citizens (Tu \& Stock McIsaac, Chapter 10). As Jung and Gunawardena argue in their first chapter, specific forms of culture newly emerge from online courses, touched upon also by Rha in Chapter 5 and Barrett in Chapter 13 .

While the complexity of the topic shows throughout the individual contributors' chapters, it is fully addressed in the editors' summarizing chapter. Terming it the cultural approach, they remind us to pay attention towards acknowledging the influence of culture on online learning and equally seeing it as a result from it. As a consequence, this perspective is to be integrated into research and, departing from here, develop and implement culturally appropriate learning environments. Considering the various contributions in this book, there is reason to assume that the cultural approach has already begun to be applied.

The seventeen chapters are compiled of theoretical considerations, empirical studies, and practice examples from the field. They primarily target culturally heterogeneous online learners and their needs and demands. For the greater part, they provide recommendations for the reader (e.g., instructional designers, lecturers, administrators, and researchers) and herewith show ways of relating theory to practice. As somewhat of an outlier, Chapter 15 by Al-Harthi presents a literature review on the field and herein shows that there is also a focus to be placed on theory building in the field in order to advance a sound body of research and practice.

As a minor point, it needs to be noticed that in the first chapter, the two editors group the book chapters under their overarching topics (e.g., "Learners, Learning, and Learner Support," "Learning Design, Identity, Gender and Technology," "Quality," and "Visual Culture"; maintaining this order also in the organization of the book would have been helpful for orientation).

And yes, this book has kept its promise of presenting a diversity of perspectives and illustrating a range of conceptions of practices and narratives already present in research and practice; herewith adding to the reader's understanding and sensitivity towards the topic. Having brought together contributors from a wide range of cultural backgrounds and experiences, the editors have indeed created a new reference in the field of culture and online learning. Considering the importance of the topics discussed and their relevance to the larger community, it would be of great value to provide open access to this book.

Stirring change in online learning for and with culturally heterogeneous student groups can only occur through sensitively adapted practice, which is informed by the types of research that the editors propose in their final chapter. Thus, reading Culture and Online Learning: Global Perspectives and Research with the perspective of what has been done and further needs to be done in research and practice, this book is a very good source, both in its own right and as a compilation of referenced sources for this field. 


\section{References}

Zawacki-Richter, O. (2009). Research areas in distance education: A Delphi study. International Review of Research in Open and Distributed Learning, 10(3), 4-20. Retrieved from http://www.irrodl.org/index.php/irrodl/article/view/674/1260

Athabasca

University

(c) () 